In conclusion, pedicled flap antropyloroplasty is an alternative surgical option for corrosive antral stricture. It can effectively widen the narrowed antrum and restore gastric tube length span for subsequent esophageal reconstruction.

\section{References}

1. Chaudhary A, Puri AS, Dhar P, Reddy P, Sachdev A, Lahoti D, et al. Elective surgery for corrosive-induced gastric injury. World J Surg. 1996;20:703-6.
2. Han Y, Cheng QS, Li XF, Wang XP. Surgical management of esophageal strictures after caustic burns: a 30 years of experience. World $J$ Gastroenterol. 2004;10:1846-9.

3. Gupta S. Surgical management of corrosive strictures following acid burns of upper gastrointestinal tract. Eur J Cardiothorac Surg. 1996; 10:934-40.

4. Zhou LH, Jiang YG, Wang RW, Lin YD, Gong TQ, Zhao YP, et al. Management of corrosive esophageal burn in 149 cases. $J$ Thorac Cardiovasc Surg. 2005;130:449-55.

5. Tabira Y, Sakaguchi T, Kuhara H, Teshima K, Tanaka M, Kawasuji M. The width of a gastric tube has no impact on outcome after esophagectomy. Am J Surg. 2004;187:417-21.

\title{
Thyroglossal duct cyst within the mediastinum: An extremely unusual location
}

Soon-Ho Chon, MD, PhD, ${ }^{\text {a }}$ Sung Ho Shinn, MD, PhD, ${ }^{a}$ Chul Burm Lee, MD, PhD, Kyung Tae, MD, PhD, ${ }^{\mathrm{b}}$ Yong Seop Lee, MD, ${ }^{\mathrm{b}}$ Si-Hyong Jang, MD, ${ }^{\mathrm{c}}$ and Seung Sam Paik, MD, PhD, ${ }^{\mathrm{c}}$ Seoul, South Korea

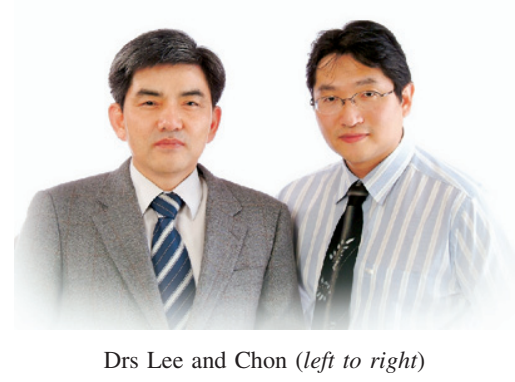

$\mathrm{T}$ he thyroglossal duct cyst (TDC) is the most common congenital cervical abnormality, occurring in up to $70 \%$ of all congenital neck abnormalities. ${ }^{1}$ In $90 \%$ of patients, it occurs in the midline. TDCs can be found anywhere between the foramen cecum at the base of the tongue to the level of the suprasternal notch. Although $85 \%$ occur below the hyoid bone, those descending below the thyrohyoid membrane are rare. ${ }^{1,2}$ In the case presented, the TDC masqueraded as a thymic mass and was the cause of much confusion. There is only 1 other reported case of TDC that even reaches the suprasternal notch. ${ }^{1}$ Our case is unique in that the TDC encroached into the superior mediastinum, descending all the way to the aortic arch. To the best of our knowledge, this is the only case of a TDC that descended into the mediastinum.

\section{Clinical Summary}

A 40-year-old woman visited our clinic with the incidental finding of a neck mass discovered after a routine examination. She had mild dysphagia, and on physical examination, a small 1-cm mass was palpable to the left of her neck just below the level of her

From the Departments of Thoracic and Cardiovascular Surgery, Otolaryngology-Head and Neck Surgery, ${ }^{\mathrm{b}}$ and Pathology, ${ }^{\mathrm{c}}$ College of Medicine, Hanyang University, Seoul, South Korea.

Received for publication Feb 1, 2007; accepted for publication Feb 7, 2007.

Address for reprints: Chul Burm Lee, MD, PhD, Department of Thoracic and Cardiovascular Surgery, College of Medicine, Hanyang University Guri Hospital, Gyonggi-Do, Guri City, Gyomun-Dong 249-1 (E-mail: cblee@hanyang.ac.kr).

J Thorac Cardiovasc Surg 2007;133:1671-2

$0022-5223 / \$ 32.00$

Copyright () 2007 by The American Association for Thoracic Surgery doi:10.1016/j.jtcvs.2007.02.012 thyroid. There was no palpable cervical lymphadenopathy. Thyroid function test results were normal, and a neck sonogram presented a well-circumscribed cystic mass at the inferior pole of the left lobe of her thyroid extending well into the thoracic inlet. A computed tomographic scan of the neck showed a large cystic mass located inferior to the left lobe of the thyroid extending into the superior anterior mediastinum, reaching the aortic arch (Figure 1). The patient was referred to our thoracic and cardiovascular department to undergo operation.

With the patient under general anesthesia, a midline transcervical incision $2 \mathrm{~cm}$ above the sternal notch was performed. There was mild adhesion to the thymus and the lower pole of the left lobe of her thyroid. Excision of the mass with the encapsulation intact was possible, and a greater portion of the stalk, seated beneath the thyroid, was removed, which was later found to be the thyroglossal tract. The cystic mass was approximately $5 \times 6 \mathrm{~cm}$.

Gross examination revealed a unilocular cystic mass with a stalk. The cut surface showed a thin fibrous wall. The cyst contained thick mucoid material. On microscopic examination, the cyst was lined by alternating respiratory and squamous epithelium. In a focal area of the cystic wall, there was a small portion of thyroid tissue completely surrounded by fibrous connective tissue (Figure 2). Smooth muscle and cartilage or submucosal gland components were absent.

The patient's postoperative course was uneventful, and there are no signs of recurrence 22 months after the operation, as evidenced by ultrasonogram examinations of her neck.

\section{Discussion}

The thyroid largely develops from a median anlage on the ventral pharyngeal wall at the second branchial arch, recognized at the end of the third week of gestation. The origin of this anlage is the foramen cecum and descends anterior to the pharynx to reach its 


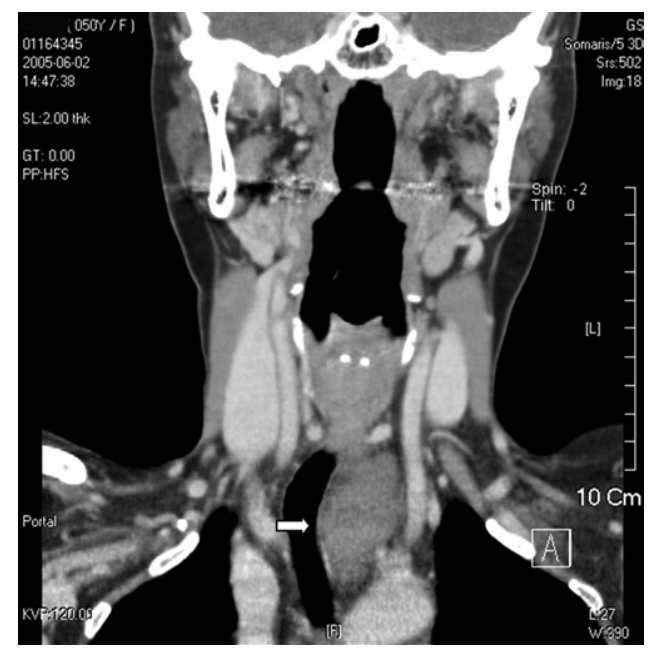

Figure 1. Computed tomographic scan of the TDC (arrow) seen extending to the level of the aortic arch.

adult site by the seventh week. By the end of the eighth week the duct usually atrophies and disappears, but persistence of this duct forms the TDC. ${ }^{3,4}$ During this migration the final destination or location is the position of the adult thyroid, and migration beyond the thyroid has been cited only in 1 other report. ${ }^{1}$ Our case is unique, because the TDC not only migrated beyond the thyroid but also reached the mediastinum.

The TDC is a slightly mobile, nontender, midline neck mass that moves with deglutition. Only $1 \%$ of TDCs are found lateral to the midline, and $80 \%$ are juxtaposed to the hyoid bone. ${ }^{3}$ TDCs are generally found in children aged less than 5 years and are uncommon in the adult. ${ }^{1,3}$ Although our case occurred laterally and in an adult, it is unique because it occurred within the mediastinum. Unfortunately, its location was the cause of confusion and erroneous diagnosis of a mediastinal mass. Because recurrence rates of TDCs vary from $8 \%$ to $40 \%$ and $1 \%$ of TDCs may undergo

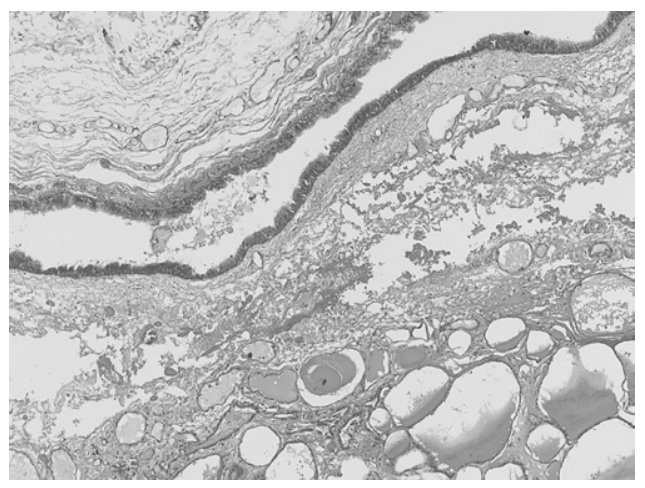

Figure 2. The cystic mass revealed a lining of pseudostratified ciliated columnar epithelium and a portion of thyroid tissue in the fibrous wall (hematoxylin-eosin stain, $\times 200$ ).

malignant transformation, definite treatment would have to include the Sistrunk procedure. ${ }^{3,4}$ Although our case shows no evidence of recurrence or malignant transformation, close observation will be imperative because of the incomplete nature of the operation performed. We believe that overall knowledge and understanding of TDCs are essential and that TDCs should be considered in the differential diagnosis of anterior mediastinal masses.

\section{References}

1. Persaud R, Short M, Kothori P, Robinson A. Thyroglossal duct cyst masquerading as a hematoma. J Laryngol Otol. 2004;118:240-1.

2. Tas A, Karasalihoglu AR, Yagiz R, Doganay L, Guven S. Thyroglossal duct cyst in hyoid bone: unusual location. J Lanryngol Otol. 2003;117: 656-7.

3. Organ GM, Organ CH Jr. Thyroid gland and surgery of the thyroglossal duct: exercise in applied embryology. World J Surg. 2000;24:886-90.

4. Sprinzl GM, Koebke J, Eckel HE, Wimmers-Klick J, Thumfart WF. Morphology of the human thyroglossal tract: a histologic and macroscopic study in infants and children. Am Otol Rhinol Laryngol. 2000; 109:1135-9. 